\title{
Indicators likely to contribute to clinical and functional improvement among survivors of politically sanctioned torture
}

\author{
Martin Hill, PhD, Mary Lynn Everson, MS, LCPC*
}

\section{Key points of interest}

- The paper introduces a holistic approach to assessing treatment programs for survivors of torture.

- Medical, psychological, and social indicators are demonstrated to correlate with, or predict clinical outcomes.

- The authors provide long-term follow-up at 24 months post-intake.

\begin{abstract}
Introduction: Heartland Alliance Marjorie Kovler Center (Kovler Center) is a torture treatment program located in Chicago, Illinois. Established in 1987, Kovler Center provides medical, mental health, and social services, as well as coordination with legal services, to a diverse population of survivors. Historically, Kovler Center used clinical measurement instruments to assess depression, anxiety and post-traumatic
\end{abstract}

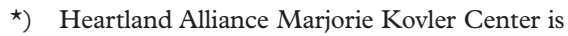
a program of Heartland Alliance International. Martin Hill, PhD, is Associate Director, Research and Evaluation and Mary Lynn Everson, MS, LCPC, is the former Senior Director, Heartland Alliance Marjorie Kovler Center.

Correspondence to: mhill@heartlandalliance.org; mleverson99@comcast.net stress, but staff was challenged with finding the best way to assess and ultimately measure changes in functional domains. The purpose of this paper is to describe (1) the Kovler Center framework, philosophical pillars, and model of treatment; (2) the comprehensive outcome evaluation program, including the Marjorie Kovler Center WellBeing Questionnaire (MKC WBQ); and (3) the results and implications to date. Methods: Kovler Center measured outcome data utilizing three instruments including a well-being tool and supplemented the data with a satisfaction survey. These instruments were administered at intake and readministered at six-month intervals up to 24 months. Results/Discussion: With nine years of data, Kovler Center can now provide valid and reliable findings in diagnostic and functional changes, with $86.6 \%$ of its clients reporting fewer symptoms of anxiety and depression, $83.1 \%$ reporting fewer symptoms of trauma, and significant improvement in employment status, housing status, and physical health after receiving services for 24 months. Indicators significantly correlated with clinical improvement at 24 months include stable housing, stable employment, region from where survivors came, English language proficiency, number of days between initial assessment and program admittance, number of services (medical, psychological, 
social) received while in the program, number of medical problems diagnosed with while in the program, and number of psychological problems diagnosed with while in the program. From the Generalized Linear Mixed Models (GLMM) analysis, the total number of psychological problems and whether or not the participant had a secure legal status while in the program were demonstrated to explain the variance in anxiety, depression, and PTSD. Females were more likely to experience depression while in the program compared to males, and participants from the Middle East were more likely to experience symptoms of depression and PTSD compared to participants from Africa. Conclusions: Since medical, psychological, and social indicators are demonstrated to correlate with or predict clinical outcomes, this highlights the need for comprehensive and holistic treatment programs for survivors of torture.

Keywords: torture treatment, holistic, evaluation, trauma, asylum seekers.

\section{Introduction}

Established in 1987, Heartland Alliance Marjorie Kovler Center (Kovler Center), a program of Heartland Alliance International, treats survivors of politically-sanctioned torture, as well as family members affected by this brutal human rights violation

(Fabri et al., 2009). Annually, 350-400 survivors representing 60 countries (89 since inception) engage in its services.

The framework for services as originally conceptualized remains in place today (Fabri et al., 2009): community-based, volunteerbased, and with no cost to survivors. Survivors seeking services are considered from an ecological perspective that includes the context of migration, adaptation, family and professional life, and trauma suffered
(Bronfenbrenner, 1979). With that in mind, Kovler Center has adopted six philosophical and aspirational pillars of service: a holistic approach to integrated services; a traumainformed approach that is empowermentfocused, strength-based, and survivor driven; an approach that is inclusive of supporting spiritual well-being (Piwowarczyk, 2005); a commitment to the provision of culturally and linguistically sensitive services; a focus on rebuilding community (Black, 2011); and access to justice.

Kovler Center's treatment model, inclusive of the framework and aspirational pillars, follows the three stages of recovery as described by psychiatrist Judith Herman (1992): the establishment of safety; remembrance and mourning, and reconnection with community and ordinary life. Clinical volunteers embrace a number of theoretical frameworks; however, all are educated in this model and encouraged to adopt it (Hill \& Everson, 2016a). Additionally, Kovler Center stresses the importance of empathy, warmth, congruence, and a therapeutic relationship as critical to positive outcomes per Lambert and Barley (2001).

As key elements of accountability, the collection and dissemination of outcome data hold Kovler Center answerable to its clients, funders, and to itself. In 2007, Kovler Center began investigating ways to track outcomes deemed important and critical to survivors of torture which included non-clinical functional domains, in addition to diagnostic. With domains identified by survivors as areas of desired change and confirmed by clinicians (immigration/legal status, physical health, employment, education, housing, English proficiency, personal relationships, emotional health), Kovler Center replaced the use of the World Health Organization 
Quality of Life Survey with its own nonclinical measurement tool that is more nuanced to the population of torture survivors that complement measures such as symptoms of anxiety, depression, and post-traumatic stress. A literature review, as detailed below, concluded that the field of torture survivor intervention rarely employs a well-being approach (Salo \& Bray, 2016).

On January 1, 2010, after a yearlong pilot period, Kovler Center formally implemented the Marjorie Kovler Center Well-Being Questionnaire (MKC WBQ) to measure and track non-clinical functional domains. At the same time, Kovler Center formally implemented the Harvard Trauma Questionnaire (HTQ) and the Hopkins Symptom Checklist-25 (HSCL) to measure clinical status during intake evaluations, with re-administration at six-month intervals up to 24 months.

\section{Literature review}

The literature describing the impact of torture treatment services, measuring change, and determining indicators of success for torture survivors is scant. Primary reasons for this are the tendency of agencies with limited resources to focus more on service delivery and treatment, as well as the conceptual, context-related, and methodological challenges present when attempting to formulate a research plan or design (Montgomery and Patel, 2011). Some treatment centers are reluctant to conduct outcomes research for fear that the research process, in terms of re-administration of any data collection instruments, is potentially re-traumatizing (Jaranson \& Quiroga, 2011).

To evaluate the services of torture treatment programs, Jaranson and Quiroga (2011) conducted an expansive literature review. Until then, most of the literature published on torture treatment programs had been descriptive in nature, and they found no studies had implemented a true experimental design. The greatest barrier to using an experimental design for measuring outcomes in torture treatment evaluation is the ethical problem that would arise by denying needed care to survivors who would be assigned to a control group (Connor, 1980; Jaranson \& Quiroga, 2011; Montgomery \& Patel, 2011; Schwartz et al., 1997). For purposes of this paper, and to be consistent with our own methodology, the focus of this literature review is on research studies that employed quasi-experimental, one group, pretest-posttest designs.

Carlsson et al. (2006a) examined 63 male traumatized refugees at a treatment center in Denmark. The researchers found that after nine months of treatment, the significant predictors of emotional distress were previous torture and trauma, lower education, no occupation, pain, and fewer social contacts. Further, the authors determined that even with the passage of extended periods of time, past torture was significantly associated with emotional distress. In a concurrent study in Denmark, Carlsson et al. (2006b) followed 139 refugee torture survivors 10 years after their referral to a treatment center. Their findings were similar, in that social relations and unemployment at follow-up were important predictors of mental health symptoms and low health-related quality of life.

In Germany, Birck (2001) reassessed a small sample $(n=21)$ of Bosnian torture survivors following two years of psychotherapy. Although PTSD symptoms had decreased within that timeframe, many of the clients continued to be symptomatic for PTSD. More recently, Stammel et al. (2017) evaluated a 
multidisciplinary approach of a treatment center in Germany. They followed 76 traumatized refugees between 7-14 months post-intake. Clients demonstrated significant improvements in symptoms of PTSD, anxiety, depression, somatoform symptoms, and quality of life. The only variable that was found to be a significant predictor was age: younger patients showed greater improvement in somatoform symptoms compared to older patients.

Kivling-Boden and Sundbom (2001; 2002) followed 27 former Yugoslavian refugees at a treatment center in Sweden following three years of program intervention. Although the authors found no differences in PTSD scores or symptoms at follow-up, they did find that unemployment, social isolation, and dependence on social welfare were associated with PTSD symptoms at follow-up. Positive factors were housing and a reasonable knowledge of the Swedish language.

Raghavan et al. (2013) evaluated a torture treatment program in New York City with a multinational refugee population. Following six months of treatment the authors found significant improvements in symptoms of PTSD, anxiety, depression, and somatization. Multivariate analysis demonstrated a strong correlation between gaining secure immigration status and clinical improvement. However, stronger predictors of clinical improvement were receiving psychotherapy and attendance at educational sessions.

Some researchers have tracked clinical symptoms of post-migratory torture survivors who received no intervention. Ekblad (2000) and Ekblad et al. (2002) studied 218 Kosovar refugees who immigrated to Sweden and measured their symptoms of anxiety, depression, and PTSD upon arrival. They followed 131 refugees at three months and 91 at six months, and found that symptoms of anxiety, depression, and PTSD were similar to baseline. Lie (2002) conducted a threeyear study of 462 mostly Bosnian refugees in Norway. Over half of the sample showed no improvement in symptoms of emotional distress, anxiety, depression, or psychological function, but did show greater symptoms of PTSD at follow-up.

\section{Methodology}

\section{Processes}

Participants in this study were admitted to Kovler Center's treatment program because they met the screening criteria for having experienced state-sponsored torture outside of the United States. At intake, three instruments, as detailed below, were administered by clinicians to gather data on both clinical and nonclinical indicators. The instruments were administered via in-person interviews at intake to all new, adult, primary and secondary survivors of torture seeking treatment at Kovler Center. The results of these intake interviews were then used as baseline measures.

Subsequent to the intake process, the Associate Director, Research and Evaluation at Kovler Center readministered the three instruments at $6,12,18$, and 24 months post-intake. Similar to intake, most follow-up interviews were conducted in-person. A couple were conducted via telephone for clients who found meeting inperson to be challenging. Clients were considered to have matriculated through the treatment program at 24 months following the completion of their initial individual treatment plan. Interpreters were provided for those clients with limited English proficiency. 
For clinical indicators, Kovler Center's outcome evaluation protocol utilized the Harvard Trauma Questionnaire (HTQ) and the Hopkins Symptom Checklist-25 (HSCL). The HTQ is a 40 -item instrument that measures the severity of trauma symptoms (Mollica et al., 1992). The first 16 items (subscale) measure the existence of Post-Traumatic Stress Disorder (PTSD) per the DSM-IV diagnostic criteria. The remaining 24 questions measure the impact that trauma has had on one's perception of their ability to function in daily life. A total score is computed by the average score of the 16 or 40 items. A score of 2.50 is considered a threshold where any score at or above this mark is symptomatic for posttraumatic stress.

The HSCL is a 25 -item instrument that measures the severity of symptoms of anxiety and depression (Hesbacher et al., 1980; Winokur et al., 1984). The first 10 items measure symptoms of anxiety and the remaining 15 items measure symptoms of depression. Similar to the HTQ above, the HSCL is administered in-person and utilizes the same four-point scale. A score of 1.75 is considered a threshold where any score at or above is deemed symptomatic for anxiety or depression.

The Marjorie Kovler Center WellBeing Questionnaire (MKC WBQ $)^{1}$ is a 49-question instrument and was utilized to measure and track multiple functional domains, or non-clinical measures, at 6-month intervals (up to 24 months) postintake and included the following:

1. Immigration (legal) status: planning to apply for asylum, not planning to

1 For the full Well-Being Questionnaire, please refer to the Torture Journal website: https:// tidsskrift.dk/torture-journal/ apply for asylum, applied for asylum, was granted asylum, refugee, legal permanent resident, U.S. citizen, or case was in appeal.

2. Employment status: (1) whether or not the client had authorization to work, and

(2) whether employed full-time, parttime, self-employed, student, stay-athome spouse, disabled, unemployed but looking for work, or unemployed and not looking for work.

3. Housing status: 10 categories ranging from homelessness to home ownership.

4. English language ability: self-reported ability to speak or read English rated on a four-point scale, where 1 was not at all well, 2 was slightly well, 3 was somewhat well, and 4 was very well.

5. Interpersonal relationships: satisfaction with how clients get along with family and friends rated on a four-point scale, where 1 was very dissatisfied, 2 was dissatisfied, 3 was satisfied, and 4 was very satisfied.

6. Physical pain/illness: whether or not clients currently had migraine headaches, pain in their joints, pain in their neck/shoulders, pain in their lower stomach, pain in their backs, numbness in their extremities, rapid heartbeat, difficulty breathing, night sweats, high blood pressures, diabetes, or digestive problems.

Further information was extracted from Kovler Center's Electronic Health Record System (EHRS) database. At intake, clinicians entered client demographic information such as gender, marital status, age at intake, country/region, level of education upon entering the program, and religion. Other information important to this analysis included time between initial assessment and program admittance, whether or not the client 
required an interpreter, number of services received while in the program (medical, psychological, social), number of medical problems while in the program, and number of psychological problems while in the program.

In addition to the three instruments described above, a satisfaction survey was also administered to clients at each re-administration. This survey provided a comprehensive assessment of clients' experiences with Kovler Center. Clients rated Kovler Center on how well the Center and its staff performed on nine specific attributes (e.g., timeliness of services, relevance of services, professionalism of staff, etc.) using a four-point scale. They also rated their overall experience with Kovler Center. Additionally, two openended questions gathered substantive qualitative feedback on Kovler Center's strengths and areas where there was opportunity to improve. The feedback gathered from this survey was used internally to continually improve the program and address any needs or issues that had arisen.

The data utilized was collected between January 1, 2010 and December 31, 2018. During that time, 441 new adult clients consented to treatment and any follow-up re-administrations to measure and track clinical progress. A total of 334 clients $(75.7 \%)$ had received at least one readministration and were entered in Kovler Center's SPSS tracking database. Because Kovler Center's approximate treatment program duration is 24 months, this study primarily focuses on 182 of the 334 (54.5\%) clients who had completed a 24 -month readministration. The 182 clients in the final sample represents $41.3 \%$ of the 441 clients who were eligible for any re-administrations, including one at 24 months.
To our knowledge, this is the first study of torture survivors participating in a holistic treatment program that compares baseline clinical measures with multiple time points, including 24 months post-baseline. Prior research studies of holistic treatment centers have focused on shorter intervals (e.g., 6 months post-intake) (Raghavan et al, 2013). The intervention period was considered optimal for demonstrating program efficacy and sustainability.

\section{Statistical analyses}

Descriptive statistics were used to provide a portrayal of client demographics, as well as the number of program services clients received while in the program, the number of medical or psychological problems with which they were diagnosed while in the program, and aggregate HSCL and HTQ measures at intake and each six-month interval following intake.

Paired sample t-tests were used to compare pre- and post- differences between HSCL and HTQ measures (total and subscale) at intake and at 24-month re-administration. For categorical data, McNemar's test was used to compare differences between pre- and postproportions. These variables came from either the MKC WBQ or the EHRS database and were dichotomized for proper comparison.

Correlations were used to measure the association between several potential predictor variables and the following clinical outcomes at 24 months: (1) HSCL anxiety subscale, (2) HSCL depression subscale, and (3) HTQ PTSD subscale. Controlling for baseline HSCL and HTQ subscale measures was important, thus partial correlation was utilized for continuous variables and partial eta squared was used for categorical variables. 
Next, we wanted to address temporal autocorrelation by looking at the clients who received a follow-up at multiple time points post-intake. All of the potential predictor variables from the correlations were entered into a Generalized Linear Mixed Model (GLMM) using a normal probability distribution and an identity link function. This method allowed us to account for the nested structure of the data where multiple outcome measures every six months nest within participants. Participants were treated as random effects and all other variables in the model (including time) were treated as fixed effects. Intraclass Correlation Coefficients (ICC) were calculated to demonstrate the variance in the dependent measures attributable to the effect of individuals. The GLMM method was chosen because it accounts for the dependency of outcome measures within individuals over time, provides an account of cluster level effects on the outcomes of interest, and preserves the sample due to missing data issues, such as HSCL or HTQ subscale measures which may be missing at 6,12 , or 18 months.

\section{Results}

Table 1 displays the characteristics of the final sample of 182 Kovler Center clients included in this analysis. The vast majority of the group was comprised of primary survivors of torture.

After 24 months in Kovler Center's treatment program, 70 clients $(38.5 \%)$ had a secure legal status, meaning they had been granted asylum $(25.3 \%)$, were legal permanent residents $(8.8 \%)$, were U.S. citizens $(3.8 \%)$, or were a refugee $(0.5 \%)$. Also, at this point, three-fourths of the sample $(n=136,74.7 \%)$ was employed (or had a spouse who was employed full-time), while $25.3 \%(n=46)$ were unemployed (including students and those who were disabled). At 24 months, $150(82.4 \%)$ clients had stable housing where they either owned their home, rented their own apartment or townhome, or contributed to rent by living in a shared space.

From their initial intake through their 24 months of treatment at Kovler Center, clients averaged 80.0 total services (range 10 to 288 , Standard Deviation $(S D)=55.3$ ), which was comprised of an average of 19.3 medical services (range 0 to $147, S D=$ 20.1), 26.5 psychological services (range 3 to $82, S D=19.4$ ), and 34.6 social services (range 2 to $188, S D=34.1$ ). Additionally, clients averaged 7.3 medical problems (range 0 to $29, S D=5.7)$ and 2.3 psychological problems (range 0 to $6, S D=1.3$ ) while in the program.

Figure 1 reveals that Kovler Center clients experienced a reduction in symptoms of anxiety, depression, and trauma from baseline to program completion (24 months). The average HSCL score decreased from 2.66 to 1.88 , and the average HTQ score declined from 2.57 to 1.87 , over the 24 -month program period. Both HSCL and HTQ total scores are considerably lower at each re-administration when compared to intake.

Figure 2 shows that the proportion of Kovler Center clients who were symptomatic for anxiety, depression, and trauma decreased notably from intake to each re-administration. For example, $94.0 \%$ of clients were symptomatic for anxiety and depression at intake; however, this proportion decreased to $50.5 \%$ at 24 months. Similarly, the proportion of clients with symptoms of trauma decreased from $54.4 \%$ at intake to $20.9 \%$ at 24 months. 
Table 1: Characteristics of the Sample $(n=182)$

\begin{tabular}{|c|c|}
\hline & $\mathrm{N}(\%)$ \\
\hline \multicolumn{2}{|l|}{ Torture Survivor Type } \\
\hline Primary & $173(95,1)$ \\
\hline Secondary & $9(4,9)$ \\
\hline \multicolumn{2}{|l|}{ Gender } \\
\hline Male & $110(60,4)$ \\
\hline Female & $72(39,6)$ \\
\hline \multicolumn{2}{|l|}{ Marital Status at 24 Months } \\
\hline Single & $92(50,5)$ \\
\hline Married & $82(45,1)$ \\
\hline $\begin{array}{l}\text { Other (divorced, separated, } \\
\text { widowed) }\end{array}$ & $8(4,4)$ \\
\hline \multicolumn{2}{|l|}{ Region } \\
\hline Africa & $137(75,3)$ \\
\hline Europe & $19(10,4)$ \\
\hline Asia & $15(8,2)$ \\
\hline Americas & $8(4,4)$ \\
\hline Middle East & $3(1,6)$ \\
\hline \multicolumn{2}{|l|}{ Religion } \\
\hline Christian & $149(81,9)$ \\
\hline $\begin{array}{l}\text { Other (Buddhist, Hindu, } \\
\text { Jewish, Muslim, other) }\end{array}$ & $32(17,6)$ \\
\hline Non-believer & $1(0,5)$ \\
\hline \multicolumn{2}{|l|}{$\begin{array}{l}\text { Employment Status at } 24 \\
\text { Months }\end{array}$} \\
\hline $\begin{array}{l}\text { Employed (full-time, part- } \\
\text { time, self) }\end{array}$ & $126(69,2)$ \\
\hline Stay at home spouse & $10(5,5)$ \\
\hline $\begin{array}{l}\text { Student (attending school } \\
\text { full-time) }\end{array}$ & $4(2,2)$ \\
\hline Disabled & $3(1,6)$ \\
\hline Unemployed & $39(21,4)$ \\
\hline
\end{tabular}

Despite the fact that roughly half of Kovler Center clients were symptomatic for anxiety and depression at 24 months, $86.6 \%$ of all clients tracked had fewer symptoms of anxiety and depression compared to intake. A similar proportion (83.1\%) had fewer

symptoms of post-traumatic stress at 24 months compared to intake.

Table 2 shows the results from paired sample $t$ tests comparing changes in HSCL and HTQ total and sub-scale scores from baseline to 24 months. Clients 
Figure 1: Change in Mean HSCL and HTQ Scores from Intake to 24 Months

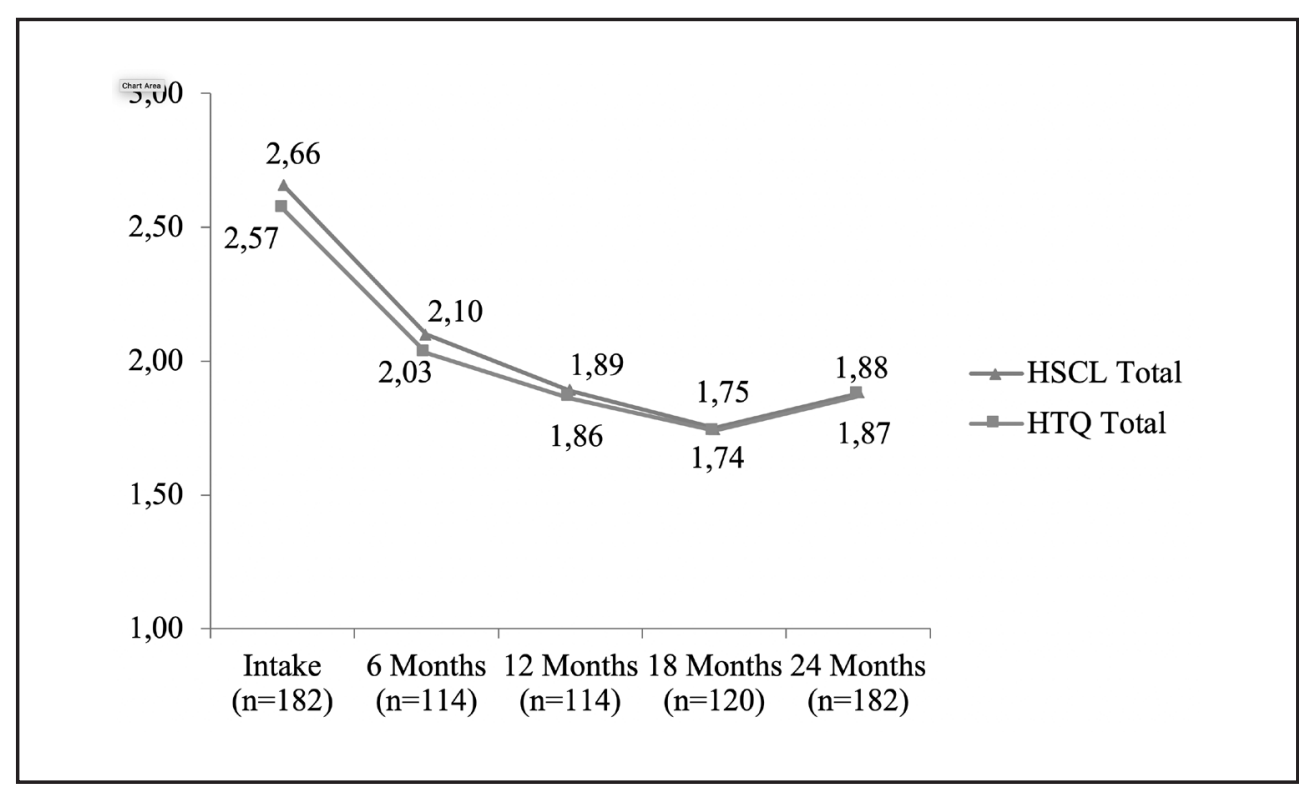

Figure 2: Change in the Proportion of Clients Who Were Symptomatic for Anxiety, Depression, and Post-Traumatic Stress from Intake to 24 Months

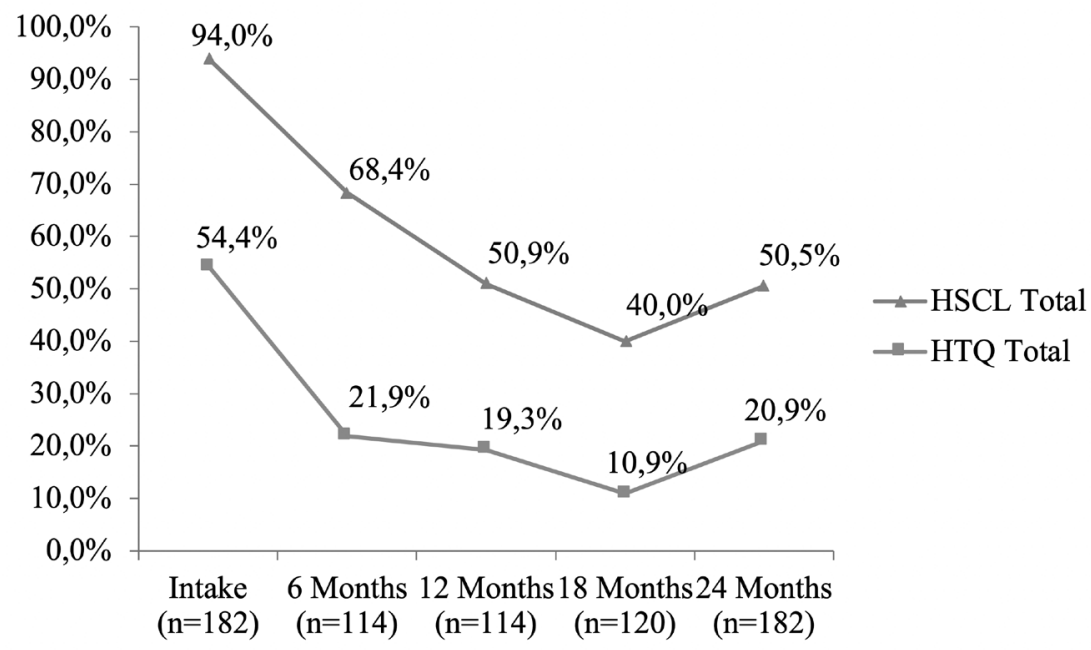


Table 2: Change in Clinical Measures Between Intake and 24-Month Re-administration

\begin{tabular}{lllllllll}
\hline Measure & & $\begin{array}{l}\text { Mean } \\
\text { Intake }\end{array}$ & $\begin{array}{l}\text { SD } \\
\text { Intake }\end{array}$ & $\begin{array}{l}\text { Mean } \\
\text { 24-Months }\end{array}$ & $\begin{array}{l}\text { SD } \\
24-M o n t h s\end{array}$ & $\mathrm{~T}$ & Cohen's d & $\mathrm{p}$ \\
\hline HSCL Anxiety & 182 & 2.49 & 0.70 & 1.77 & 0.65 & 12.52 & .93 & $<.001$ \\
& & & & & & & & \\
$\begin{array}{l}\text { HSCL Depres- } \\
\text { sion }\end{array}$ & 182 & 2.77 & 0.66 & 1.93 & 0.71 & 14.27 & 1.06 & $<.001$ \\
HSCL Total & 182 & 2.66 & 0.62 & 1.88 & 0.66 & 14.55 & 1.08 & $<.001$ \\
HTQ DSM-IV & 182 & 2.78 & 0.62 & 1.93 & 0.67 & 14.26 & 1.06 & $<.001$ \\
HTQ Total & 182 & 2.57 & 0.61 & 1.87 & 0.63 & 13.07 & .97 & $<.001$
\end{tabular}

Note: HSCL scores represent average score for total and each subscale of the Hopkins Symptoms Checklist-25 and HTQ scores represent average scores for total and a subscale for the Harvard Trauma Questionnaire.

demonstrated a statistically significant reduction in clinical symptoms of anxiety, depression, and PTSD ( $\mathrm{p}=<.001)$ while receiving treatment in the Kovler Center program. Further, the elevated Cohen's d scores show large effect sizes, indicating strong relationships between the pre- and post- measures.

As previously mentioned, in addition to tracking clinical symptoms of anxiety, depression, and trauma, Kovler Center tracks several non-clinical indicators of functional well-being via its MKC WBQ. In order to compare the non-clinical indicators from baseline to 24 months, which were categorical, McNemar's test for paired proportions was used (see Table 3 below).

With regard to legal status, there was an increase in the percentage of clients who applied for asylum at $6,12,18$, and 24 months compared to intake. More importantly, there was a significantly greater percentage of clients who had secure legal status (granted asylum, permanent legal residence, or U.S. citizen) at 24 months compared to intake; $11.5 \%$ had secure legal status at intake compared to $38.5 \%$ at 24 months.
Stable and adequate housing is always a major concern for Kovler Center clients. Homelessness and unstable housing situations understandably complicate efforts towards symptom reduction and improved health. However, there was improvement in the housing status of many of the clients. The proportion of clients who contributed rent to either their own apartment, home, or shared space, or who owned their home, increased significantly from $25.3 \%$ at intake to $82.4 \%$ at the 24 -month interval. There was also a reduction in the percentage of clients living in shelters or other non-ideal housing (e.g. garage, storage room, etc.) at the 12,18, and 24-month follow-ups, compared to intake.

Employment status also improved for many clients. Three in ten $(29.1 \%)$ had authorization to work at intake, compared more than three-fourths $(79.7 \%)$ at 24 months. More impressively, whereas $19.8 \%$ of clients were employed in either a full-time job, part-time job, or were selfemployed at intake, $74.7 \%$ were employed at the 24-month interval.

Kovler Center clients' personal relationships also improved. When asked to describe their satisfaction with their 
Table 3: Change from Baseline to 24-Month Re-administration Among Functional Indicators from the MKC Well-Being Questionnaire (WBQ)

\begin{tabular}{lll}
\hline Baseline & 24-Month \\
& (Intake) & Re-administration \\
& $\mathrm{N}(\%)$ & $\mathrm{N}(\%)$ \\
\hline
\end{tabular}

\section{Legal Status}

Secure (granted asylum, refugee, legal

$21(11.5)$

$70(38.5)^{\star \star}$

permanent resident, U.S. citizen)

\section{Housing Status}

Able to contribute to rent or own home

$46(25.3)$

$150(82.4)^{\star \star}$

\section{Employment Status}

Authorization to work (work permit)

$36(19.8)$

$145(79.7)^{\star \star}$

Employed (full time, part-time, self)

\section{Interpersonal Relationships $\star \star \star ~$}

Satisfied with interaction with friends

$123(76.4)$

$.0)^{\star}$

Satisfied with interaction with family

$118(70.7)$

$156(90.2)^{\star}$

\section{English Language Ability}

Speak English well (somewhat/very)

$107(58.8)$

$104(57.1)$

Read English well (somewhat/very)

$121(66.5)$

$137(75.3)^{\star}$

\section{Physical Health (Currently Have)}

Chronic/frequent migraine headaches

$\begin{array}{ll}141(77.5) & 73(40.1)^{\star \star} \\ 108(59.3) & 83(45.6)^{\star} \\ 90(49.5) & 77(42.5) \\ 72(39.6) & 57(31.3) \\ 120(65.9) & 108(59.3) \\ 72(39.6) & 56(30.8) \\ 113(62.1) & 58(31.9)^{\star \star} \\ 81(44.5) & 40(22.1)^{\star \star} \\ 88(48.4) & 36(19.8)^{\star \star} \\ 77(42.3) & 43(23.9)^{\star \star} \\ 26(14.3) & 36(20.0) \\ 13(7.1) & 15(8.3)\end{array}$

Pain in joints

Pain in neck/shoulders

Pain in lower stomach

Pain in back

Numbness in arms, legs, feet, or hands

Racing heartbeat

Difficulty breathing

Night sweats

Digestive problems

High blood pressure

Diabetes

$\star \star<.001 ;{ }^{\star}<.01, \mathrm{McNemar}$ test; ${ }^{\star \star \star}$ The sample size for this variable is less than 182 because some clients report having no friends or family with whom they interact. 
relationships with friends and family, the percentage of clients who replied "satisfied" or "very satisfied" increased from $76.4 \%$ to $91.0 \%$ and from $70.7 \%$ to $90.2 \%$ with regard to friends and family, respectively.

The proportion of clients who reported they spoke English "somewhat well" or "very well" does not appear to improve much over time. For clients with another primary language, more sizeable progress is made in their ability to read English while in the program.

The domain of physical health improved for several conditions as well. Compared to intake, there was a significant reduction in the percentage of clients who reported experiencing migraine headaches, joint pain, racing heartbeat, breathing difficulties, night sweats, and digestive problems at the 24-month interval. Specifically, the percentage of clients experiencing migraines dropped from $77.5 \%$ at intake to $40.1 \%$ at the 24-month re-administration, while the proportion of clients reporting a racing heartbeat declined from $62.1 \%$ at intake to $31.9 \%$ at 24 months. Conversely, the proportion of clients with hypertension increased over time. At intake, $14.3 \%$ of clients reported hypertension, which increased to $20.0 \%$ at 24 months.

The above analysis demonstrates marked improvement in both clinical and nonclinical measures. Thus, the association between specific variables and clinical outcomes will be subsequently explored. Table 4 below illustrates the correlation between potential predictor variables and HSCL subscale scores for anxiety and depression and the HTQ subscale score for PTSD at 24 months. Partial correlation and partial eta squared were used to control for baseline subscale scores.

Several variables were associated with clinical improvement on the three subscales. Lower HSCL anxiety scores at 24 months were associated with: (1) shorter wait times between initial assessment and program admittance (individual treatment plan completed), (2) English language proficiency, (3) stable employment, (4) stable housing, (5) fewer services (medical, psychological, social), and (6) fewer medical problems while in the program.

Lower HSCL depression scores at 24 months were associated with: (1) stable housing, (2) fewer medical services, and (3) fewer psychological problems. Additionally, Kovler Center clients from Middle Eastern or Asian countries had higher HSCL depression scores at 24 months compared to clients from Africa, Europe, or the Americas.

With regard to post-traumatic stress, lower HTQ-DSM-IV scores at 24 months were associated with: (1) shorter wait times between initial assessment and program admittance, (2) stable housing, and (3) fewer psychological problems.

In sum, clients who were in an unstable housing situation at 24 months were more likely to have symptoms of anxiety, depression, and PTSD compared to clients with more stable housing. Longer duration between intake and the first individual treatment plan was associated with greater symptoms of anxiety and PTSD at 24 months. Clients who required more medical services were more likely to be symptomatic for anxiety and depression at 24 months and clients who had more psychological problems were more likely to be symptomatic for depression and PTSD at 24 months. Additionally, clients who were more likely to be symptomatic for anxiety at 24 months were: (1) not proficient in the English language and required an interpreter, (2) not in a stable employment situation, (3) more likely to 
Table 4: Association Between Predictor Variables and Psychological Distress at 24 Months $(n=182)$

\begin{tabular}{|c|c|c|c|}
\hline & $\begin{array}{l}\text { HSCL } \\
\text { Anxiety }\end{array}$ & $\begin{array}{l}\text { HSCL } \\
\text { Depression }\end{array}$ & $\begin{array}{l}\text { HTQ } \\
\text { DSM-IV }\end{array}$ \\
\hline Gender $^{1}$ & .00 & .00 & .00 \\
\hline Age at intake ${ }^{2}$ & .09 & .11 & .08 \\
\hline Marital status (married/not married) ${ }^{1}$ & .00 & .00 & .00 \\
\hline Level of education (college/no college) ${ }^{1}$ & .00 & .00 & .00 \\
\hline Region $^{1}$ & .04 & $.07^{\star}$ & .05 \\
\hline $\begin{array}{l}\text { Number of days between initial intake and program admit- } \\
\text { tance (initial ITP) }{ }^{2}\end{array}$ & $.19^{\star}$ & .12 & $.17^{\star}$ \\
\hline Interpretation required $^{1}$ & $.07^{\star \star}$ & .02 & .02 \\
\hline Secure legal status while in program ${ }^{1}$ & .02 & .02 & .02 \\
\hline Religion (Christian/non-Christian $)^{1}$ & .01 & .00 & .02 \\
\hline Stable employment ${ }^{1}$ & $.04^{\star \star}$ & .01 & .01 \\
\hline Stable housing ${ }^{1}$ & $.04^{\star}$ & $.05^{\star \star}$ & $.03^{\star}$ \\
\hline \multicolumn{4}{|l|}{ Number of services } \\
\hline Medical $^{2}$ & $.21^{\star \star}$ & $.15^{\star}$ & .13 \\
\hline Psychological $^{2}$ & $.19^{\star}$ & .14 & .12 \\
\hline Social $^{2}$ & $.15^{\star}$ & .09 & .07 \\
\hline TOTAL $^{2}$ & $.22^{\star \star}$ & .14 & .12 \\
\hline Total number of medical problems while in program ${ }^{2}$ & $.15^{\star}$ & .11 & .15 \\
\hline Total number of psychological problems while in program ${ }^{2}$ & .13 & $.15^{\star}$ & $.21^{\star \star}$ \\
\hline
\end{tabular}

Note: ${ }^{\star}$ correlation is significant at the .05 level (2-tailed), ${ }^{\star \star}$ correlation is significant at the .01 level (2-tailed) ${ }_{1}$ Partial Eta Squared, ${ }_{2}$ Partial Correlation.

have had a greater number of medical problems, and (4) more likely to have received greater numbers of psychological, social, and total services compared to clients with fewer symptoms of anxiety. There was no association between gender, marital status, level of education, religion, age at intake, or having a secure legal status and symptoms of anxiety, depression, or PTSD at 24 months.

Next, all of the potential predicter variables from the correlation step were included in a Generalized Linear Mixed Model (GLMM) with all five time points where clients were assessed (intake, 6, 12, 18 , and 24 months).
Table 5 below contains output from a GLMM model with HSCL anxiety, HSCL depression, and HTQ PTSD subscale scores as the dependent variables. Anxiety scores were $.61 S D$ lower at 6 months, $.90 S D$ lower at 12 months, $1.09 S D$ lower at 18 months, and $.97 S D$ lower at 24 months, compared to anxiety at baseline. Clients without a secure legal status displayed anxiety scores $.20 S D$ higher than clients with a secure legal status. Additionally, for each additional $S D$ of psychological problems participants had while in the program, anxiety was $.13 S D$ higher. The Intraclass Correlation Coefficient (ICC) shows that $41.8 \%$ of the variance in anxiety is explained by the individual. 
Table 5: Mixed Model Predicting Anxiety, Depression, and PTSD Symptoms in Treatment Center Participants

\begin{tabular}{|c|c|c|c|c|c|c|}
\hline & Anxiety & & Depressior & & PTSD & \\
\hline & $B$ & $p$ & $B$ & $p$ & $B$ & $p$ \\
\hline Time 2 (6-Month) a & -.612 & $<.001$ & -.840 & $<.001$ & -.929 & $<.001$ \\
\hline Time 3 (12-Month) a & -.897 & $<.001$ & -1.082 & $<.001$ & -1.132 & $<.001$ \\
\hline Time 4 (18-Month) ${ }^{a}$ & -1.090 & $<.001$ & -1.199 & $<.001$ & -1.292 & $<.001$ \\
\hline Time 5 (24-Month) a & -.974 & $<.001$ & -1.109 & $<.001$ & -1.155 & $<.001$ \\
\hline Gender (Female) ${ }^{b}$ & .105 & .256 & .203 & .021 & .119 & .178 \\
\hline Age at intake & -.054 & .309 & -.002 & .969 & -.046 & .343 \\
\hline Marital status (not married) ${ }^{c}$ & .053 & .654 & .074 & .532 & .028 & .798 \\
\hline Education (no college education) ${ }^{d}$ & .051 & .597 & .050 & .586 & .078 & .390 \\
\hline Region $=5$ (Americas) $^{\mathrm{e}}$ & .168 & .416 & .098 & .711 & .054 & .837 \\
\hline Region $=4(\text { Asia })^{\mathrm{e}}$ & .421 & .081 & .291 & .151 & .279 & .267 \\
\hline Region $=3$ (Europe) ${ }^{\mathrm{e}}$ & .148 & .459 & -.021 & .918 & .048 & .817 \\
\hline Region $=2(\text { Middle East })^{\mathrm{e}}$ & .616 & .089 & .952 & .031 & .823 & .040 \\
\hline Days between intake and ITP & .039 & .472 & .038 & .420 & -.005 & .914 \\
\hline Interpretation not required ${ }^{\mathrm{f}}$ & -.213 & .061 & -.168 & .143 & -.163 & .128 \\
\hline $\begin{array}{l}\text { Legal status (no secure legal } \\
\text { status) } g\end{array}$ & .202 & .035 & .289 & .002 & .215 & .014 \\
\hline Religion (non-Christian) ${ }^{\mathrm{h}}$ & .031 & .835 & .026 & .862 & -.021 & .887 \\
\hline $\begin{array}{l}\text { Employment (no stable employment) } \\
\text { i }\end{array}$ & .198 & .108 & .045 & .689 & .120 & .291 \\
\hline Housing (no stable housing) ${ }^{j}$ & .015 & .910 & .131 & .322 & .077 & .561 \\
\hline Total medical services & .004 & .929 & .053 & .274 & .031 & .396 \\
\hline Total social services & -.179 & .261 & -.157 & .310 & -.226 & .113 \\
\hline Total psychological services & -.020 & .849 & -.002 & .985 & .023 & .820 \\
\hline Total all services & .290 & .208 & .189 & .408 & .236 & .243 \\
\hline Total medical problems & .073 & .181 & .037 & .516 & .067 & .218 \\
\hline Total psychological problems & .127 & .006 & .133 & .005 & .143 & .001 \\
\hline $\mathrm{N}$ & 711 & & 711 & & 711 & \\
\hline Respondents & 182 & & 182 & & 182 & \\
\hline AIC & 1693.363 & & 1632.860 & & 1630.646 & \\
\hline $\mathrm{BIC}$ & 1702.407 & & 1641.904 & & 1639.690 & \\
\hline ICC & .418 & & .444 & & .404 & \\
\hline
\end{tabular}

Note: ${ }^{\mathrm{a}}$ Compared to baseline (intake); ${ }^{\mathrm{b}}$ Compared to male; ${ }^{\mathrm{c}}$ Compared to married; ${ }^{\mathrm{d}}$ Compared to some college education/college degree; ${ }^{\mathrm{e}}$ Compared to Africa; ${ }^{\mathrm{f}}$ Compared to interpretation required; ${ }^{\mathrm{g}}$ Compared to secure legal status; ${ }^{\mathrm{h}}$ Compared to Christian; ${ }^{\mathrm{i}}$ Compared to stable employment; ${ }^{\mathrm{i}}$ Compared to stable housing. 
Depression scores were $.84 S D$ lower at 6 months, $1.08 S D$ lower at 12 months, $1.20 S D$ lower at 18 months, and 1.11 $S D$ lower at 24 months, compared to depression scores at baseline. Female participants had depression scores .20 $S D$ higher than male participants. Clients from the Middle East demonstrated depression scores .95 SD higher than clients from Africa. Clients without a secure legal status displayed depression scores .29 SD higher than clients with a secure legal status. Additionally, for each additional SD of psychological problems participants had while in the program, depression was .13 higher. The Intraclass Correlation Coefficient (ICC) shows that $44.4 \%$ of the variance in anxiety is explained by the individual.

PTSD scores were $.93 S D$ lower at 6 months, $1.13 S D$ lower at 12 months, $1.29 S D$ lower at 18 months, and 1.16 $S D$ lower at 24 months, compared to PTSD scores at baseline. Clients from the Middle East demonstrated PTSD scores $.82 S D$ higher than clients from Africa. Clients without a secure legal status displayed PTSD scores .22 SD higher than clients with a secure legal status. Additionally, for each $S D$ of psychological problems participants had while in the program, PTSD was .14 SD higher. The Intraclass Correlation Coefficient (ICC) shows that $40.4 \%$ of the variance in anxiety is explained by the individual.

As previously mentioned, in conjunction with tracking the progress of clients with respect to symptoms of anxiety, depression, PTSD, and functional well-being, Kovler Center gathers and tracks feedback from clients via satisfaction surveys.

In addition to rating Kovler Center staff and service on specific attributes, clients were asked an open-ended question about the services that had been the most helpful to them while in the Kovler Center program. Although they reported myriad services that were helpful to them, medical services (including primary care, medication, medical insurance, psychiatric services) and mental health services (including counseling, psychotherapy) were cited most often. Other program aspects considered helpful were the staff (professional, caring, friendly, responsive), legal assistance (assisting them in the asylum process), and assistance with dental needs, transportation, and food.

Conversely, clients were asked about ways in which Kovler Center could improve or create better client experiences. Approximately six in ten could not, or did not, offer any suggestions for improvement. Those who did offered suggestions such as Kovler Center staff could be better at: (1) following through on appointments/plans, (2) assisting with housing and employment issues, and (3) assisting them with medical issues. They also said they would like to see wait time for services reduced.

\section{Discussion}

This study has expanded on the existing, but limited, research on the evaluation of torture treatment programs using a quasiexperimental, one group, pretest-posttest design to measure outcomes. Several prior studies have shown program effectiveness in terms of clinical symptom reduction but have measured symptom changes over shorter periods of time (Raghavan et al., 2013; Stammel et al., 2017) and/or have not measured anxiety, depression, and PTSD symptom changes together (Birck, 2001; Kivling-Boden \& Sundbom, 2001; 2002). Our approach was to investigate Kovler Center program efficacy up to 24 months, which is considered to be 
the duration for clients who matriculate through the core program.

In general, clients demonstrated significant improvement in both clinical and non-clinical measures while in Kovler Center's multidisciplinary treatment program. Clients saw a notable reduction in symptoms of anxiety, depression, and PTSD from intake through 24 months of treatment, with the greatest improvement occurring within the first six months, but continuing throughout.

Moreover, clients improved in a number of functional well-being domains while in the program, some of which have been shown in the research literature on torture treatment to be associated with clinical outcomes, such as employment (Carlsson et al, 2006a;2006b; KivlingBoden \& Sundbom, 2001; 2002). Among this sample, employment status improved significantly as clients received work permits and were able to find part- or -full-time employment. They were also able to secure stable housing as they became able to contribute to rent and move out of temporary living situations. It is important to emphasize that despite the significant increase in the proportion of clients employed while in the program, Kovler Center clients generally struggle to find adequate, steady employment.

Kovler Center clients became more satisfied with their personal relationships during their time in the treatment program. Many of those with limited English proficiency skills demonstrated improvement in this area even though they were often less generous when evaluating their own English language ability.

Clients experienced a reduction in a number of physical ailments while in the program. The prevalence of psychosomatic experiences such as migraine headaches, bodily pain, racing heartbeat, night sweats, breathing difficulties, and digestive problems decreased significantly from intake to 24 months in the program.

Clients did not see comparable improvement with regard to diabetes or high blood pressure. Research has demonstrated direct links between the experience of trauma, or PTSD, and both hypertension (Heim \& Nemeroff, 2001; Kibler et al., 2009) and diabetes (Kinzie et al., 2008) or comorbid conditions such as obesity (Vieweg et al., 2007). In some people these chronic conditions may also be explained by the natural process of aging or poor dietary choices that, once onset occurs, are often irreversible.

A number of variables were significantly correlated with clinical outcomes at 24 months. Stable housing was associated with clinical improvement for anxiety, depression, and PTSD. Stable employment was also associated with anxiety, as well as English language proficiency, number of medical problems while in the program, and the number of services received while in the program (medical, psychological, social). The number of days between intake and program admittance was associated with both anxiety and PTSD.

The number of psychological problems participants experience while in the program predicted symptoms of anxiety, depression, and PTSD; the greater the number of diagnosed psychological problems, the higher the measures for anxiety, depression, and/or PTSD. Thus, despite program intervention, participants with multiple psychological problems are less likely to see a decline in their symptomology for anxiety, depression, or PTSD. However, the reduction in these clinical outcome measures over time is far greater in magnitude than the effect 
of psychological problems; participants with fewer psychological problems can expect to see their symptoms of anxiety, depression, or PTSD decline more rapidly compared to participants with more psychological problems.

Legal status was also a predictor of symptoms of anxiety, depression, and PTSD; participants with a secure legal status (e.g., granted asylum, legal permanent resident) were more likely to experience positive clinical outcomes compared to participants without a secure legal status. This finding is consistent with previous research on torture treatment programs (Hill \& Everson, 2016b; Raghavan et al., 2013), although these did not employ a GLMM.

This is an important finding but a challenge for treatment centers who have participants going through the asylum process. Wait times for asylum hearings have been increasing over the past few years and it is now uncommon for Kovler Center participants to receive asylum while they are in the 24-month program. Even though a significantly greater proportion of Kovler Center clients have a secure legal status at 24 months compared to intake, of the 161 clients in the sample who did not have a secure legal status at intake, only $50(31.1 \%)$ did so upon program completion. It is evident from participants statements during follow-up interviews the difficulties and frustrations of the asylum process are negatively impacting their well-being. Therefore, it is important to take special note of this political and legal phenomenon, monitoring it as research to evaluate the program.

Clients from the Middle East were more likely to experience symptoms of depression and PTSD while in the program compared to African clients. This difference might be explained by the fact that Kovler Center has a more difficult time providing interpreters for Arabic-speaking clients than, for example, French-speaking clients. Difficulty finding interpreters for certain languages often results in participants experiencing longer wait times for services and program admittance.

The finding that women are more likely than men to demonstrate higher depression measures is consistent with other research on survivors of torture (Spiric, et al., 2010) and trauma (Haskell, et al., 2010).

The GLMM allowed determination of the variables predict clinical outcomes over time in participants who were in the treatment program. The Intraclass Correlation Coefficient suggests that there is a substantial amount of dependency in anxiety, depression, and PTSD scores within individuals, which is to be expected in longitudinal studies.

Through the Kovler Center's holistic approach to torture treatment, staff are able to address, at least to some degree, many of the variables that impact client well-being. For example, steps can be taken to ensure that interpretation services will continue to be utilized and more efforts will be made to find interpreters for less common languages (e.g., Arabic, Tigrinya, Nepalese, Mongolian) to offset delayed services and longer wait times to program admittance. Second, staff can continue to connect clients to community resources that assist them in finding English as a Second Language classes to improve their English proficiency, stable employment and stable housing. Finally, Kovler Center therapists and primary care staff will continue to provide the mental and physical health treatment services that clients report are most important to them. 


\section{Limitations}

A key limitation to this study is the lack of a control group; either true or quasi. However, as stated in the literature review this is consistent with the evaluation of torture treatment programs because of the ethical dilemma of denying some people needed intervention. This is especially true for torture treatment programs that generally operate with an ethos to provide treatment to every survivor who requests care (Jaranson \& Quiroga, 2011).

An alternative to utilizing a true control group is to implement a quasiexperimental design with two groups--an experimental group and a control group-whose subjects are not randomly assigned to either one. The control group serves as a comparison group. This also has limitations as the two groups may be very different at baseline. A potential comparison group could be wait-listed clients whose outcomes are measured at a specific time and compared to the experimental group. Although Kovler Center does have a wait list, most clients are eventually admitted to the program within three months. Therefore, this option would not have been very useful for our purposes since they would not have been available for comparison at the first follow-up which occurs at six months.

In the absence of a true control group, it is impossible to rule out the impact of variables on treatment success that are outside of the treatment program. For example, symptom reduction and clinical improvement could be a product of the passage of time. However, by implementing a GLMM approach an attempt was made to account for time by controlling for autocorrelation. Further, clients have told Kovler Center staff anecdotally during the re-administration interview process that other factors, for example, attending a welcoming church, living with friendly people who have taken them in, living with relatives or people from their home country, and finding housing, employment, or other services and programs on their own without Kovler Center assistance, have been helpful in their recovery. That said, Kovler Center clients most often report that the medical assistance and mental health therapy they receive has been most helpful to their improvement. This is consistent with symptom reduction while in the treatment program. It might be worthwhile to add a question to the satisfaction survey related to influencing factors outside of Kovler Center as survivors do note these factors that have been helpful.

It is desirable to know which specific services, what type of treatment modality, or which therapist characteristics, if any, have greater impacts on clinical improvement than others. As stated previously, although all staff and clinical volunteers are oriented to the philosophical pillars and to Judith Herman's model, pro bono psychotherapists follow a number of therapeutic approaches and utilize interventions based on what the individual survivor presents, making it a challenge to tie any outcome to the therapeutic approach. And yet, in utilizing Herman's stages even in combination with diverse forms of trauma treatment, this provides a valuable orientation to the concerns of torture survivors and could be measured as such (Gorman, 2001).

There are certain variables that may impact treatment success, such as age at first experience of torture or duration of torture that were not included in our model because this information was lacking for some of our earliest clients being tracked. Going forward, 
the importance of these variables will be explored as they relate to program success. Many data points related to torture history have been recently added to the intake evaluation in the EHRS.

In tracking outcomes, a slight increase in clinical symptoms for anxiety, depression, and PTSD from 18 months to 24 months was noted. McFarlane and Kaplan (2012) reviewed 40 studies from 1980 to 2010 and found that most treatment effects lasted from 3 to 18 months. It may be that clients receiving services at 24 months are those most in need of services. It could also represent increased stress due to the length of time for adjudication of their asylum cases. It is important to explore this further because it may also be evidence that there are diminishing returns on the effectiveness of treatment for torture survivors beyond 18 months. If this found to be the case, it would be critical to Kovler Center and other torture treatment centers that have limited resources.

Lastly, this study could have benefitted from a larger sample. In the methodology, it was stated $41.3 \%$ of all clients eligible for re-administrations complete one at 24 months. However, since Kovler Center does not require the completion of re-administrations in order to receive needed care, it can often be challenging to persuade clients to participate. There are many reasons for their lack of participation in these interviews, including the fact that many are busy with school, work, family life, etc., at this point in their lives. Others may find the follow-up interviews triggering to their anxiety, depression, or PTSD. Further, some clients are simply not engaged in services and their case remains open for the sole purpose of ensuring there are no problems with their pending legal case. In the future better ways will be sought to encourage participation more consistently in the re-administrations, perhaps by providing additional incentives.

\section{Conclusion}

Despite some limitations to this research, as well as the ethical and practical challenges in conducting rigorous scientific studies of torture survivors, torture treatments centers are encouraged to conduct any, and as much research as possible, in order to build on the limited existing research literature (Jaranson \& Quiroga, 2011). The impact of social factors in a torture survivor's wellbeing demonstrates the relevance of our multidisciplinary or holistic approach. Other researchers have shown the importance of a comprehensive approach (e.g., wraparound) to treating survivors of torture, focusing especially on non-clinical factors such as housing, employment, and immigration status (Kira, 2002).

It is also important to point out that the goal, or mission, of Kovler Center is to help clients improve and not necessarily become asymptomatic for clinical measures of anxiety, depression, and PTSD. Even though many clients are still symptomatic for clinical symptoms after 24 months of intervention, this is not uncommon for torture survivors (Birck, 2001). More importantly, the vast majority of clients have demonstrated significant improvement compared to when they entered Kovler Center for treatment. Some have suggested that when studying torture survivors, it might be more important to look at functioning as an outcome, rather than the level of clinical symptoms (World Health Organization, 2001).

For torture survivors, rehabilitation is a complex and recurrent process because their situation is often chronic and their course of recovery is often set back by recurrence of symptoms, as many factors 
can trigger clinical symptoms. It is also challenging for treatment centers to formulate a treatment plan that meets the needs of people from many different countries and cultural backgrounds.

The findings of this research are important to the field and are consistent with findings of other studies on torture treatment programs. Despite the lack of a control group the treatment program is helping Kovler Center clients recover in many ways. Increasing the evaluation period to cover the entire duration of program intervention at Kovler Center (e.g., 24 months) aids staff in appropriately assessing the program's success and expands on the existing research in the field of torture treatment.

\section{Acknowledgements}

The authors are grateful to Marianne Joyce, LCSW, Social Services Manager at Kovler Center who offered to jump start our outcome evaluation process, and to Ruth Ross, $\mathrm{PhD}$, volunteer evaluation consultant at Kovler Center who provided expert guidance during the pilot period. We are eternally grateful to the survivors we serve and who inspire us every day.

\section{References}

American Psychiatric Association, Committee on Nomenclature and Statistics. (1994). Diagnostic and Statistical Manual of Mental Disorders, Fourth Edition. Washington, DC: American Psychiatric Association.

Amnesty International. Amnesty International Annual Report. 2016.

Birck, A. (2001). Torture victims after psychotherapy: A two year follow-up. Torture, 11(2), 55-58.

Black, M. (2011). From kites to kitchens: Collaborative community-based occupational therapy with refugee survivors of torture. In Kronenberg, F, Pollard, N, \& Sakellariou, D, (Eds.), Occupational Therapies Without Borders: Towards an Ecology of Occupation-Based Practices (2), 217-224.

Bronfenbrenner, U. (1979). The ecology of human development. Cambridge: Harvard University Press.

Carlsson, J. M., Mortensen, E. L., \& Kastrup, M. (2006a). Predictors of mental health and quality of life in male tortured refugees. Nordic Fournal of Psychiatry, 60(1), 51-57. doi/ full/10.1080/08039480500504982

Carlsson, J. M., Olsen, D. R., Mortensen, E. L., \& Kastrup, M. (2006b). Mental health and healthrelated quality of life: A 10-year follow-up of tortured refugees. Fournal of Nervous and Mental Disease, 194(10),725-731. doi:10.1097/01. nmd.0000243079.52138

Connor, Ross F. (1980). Ethical issues in the use of control groups. New Directions for Program Evaluation, 7,63-75. doi.org/10.1002/ev.1253

Ekblad, S. (2000). A survey of somatic, psychological, and social needs of mass displaced refugees from the Kosovo province while in Sweden. Stress Research Reports, 293, Stockholm.

Ekblad, S., Prochazka, H., \& Roth, G. (2002). Psychological impact of torture: A 3-month follow-up of mass-evacuated Kosovan adults in Sweden: Lessons learnt for prevention. Acta Psychiatrica Scandinavica, 106(412), 30-36. doi. org/10.1034/j.1600-0447.106.s412.7.x

Fabri, M. (2001). Reconstructing safety: Adjustments to the therapeutic frame in the treatment of survivors of political torture. Professional Psychology: Research and Practice, 32(5), 452-457. doi/10.1037/0735-7028.32.5.452

Fabri, M., Joyce, M., Black, M., \& Gonzalez M. (2009). Caring for torture survivors: The Marjorie Kovler Center. In Stout, C. (Ed.) The New Humanitarians. Westport, Connecticut, London: Praeger, 157-187.

Gorman, W. (2001). Refugee survivors of torture: trauma and treatment. Professional Psychology: Research and Practice, 32(5), 443-451. doi/10.1037/0735-7028.32.5.443

Harvard Trauma Questionnaire, 2018. [Internet] Available from: http://hprt-cambridge.org/ screening/harvard-trauma-questionnaire/

Haskell, S.G., Gordon, K.S., Mattocks, K., Duggal, M., Erdos, J., Justice, A. \& Brandt, C.A. (2010). Gender differences in rates of depression, PTSD, pain, obesity, and military sexual trauma among Connecticut war veterans or Iraq and Afghanistan. Fournal of Women's Health, 19(2), 267-271. doi: 10.1089/jwh.2008.1262

Heim, C., \& Nemeroff, C. B. (2001). The role of childhood trauma in the neurobiology of mood and anxiety disorders: Preclinical and clinical studies. Biological Psychiatry, 49(12), 1023-1039. https://doi.org/10.1016/S0006-3223(01)01157-X Herman, J. L. (1992). Trauma and Recovery. New 
York: Basic Books.

Hesbacher P. T., Rickels K., Morris R. J., Newman, H., \& Rosenfeld, H. (1980). Psychiatric illness in family practice. Fournal of Clinical Psychiatry, 41, 6-10. Retrieved from https://www.ncbi.nlm.nih. gov/pubmed/7351399

Higson-Smith, C. (2015). Updating the estimate of refugees resettled in the United States. St. Paul, MN: Center for Victims of Torture.

Hill, M., \& Everson, M. L. (2016a). The healing impact: Heartland Alliance Marjorie Kovler Center services for survivors of politically-sanctioned torture. Chicago, IL: Heartland Alliance International.

Hill, M., \& Everson, M. L. (2016b). Efficacy of rehabilitation and treatment approaches: Indicators likely to contribute to treatment success among survivors of torture. Paper presented at the International Rehabilitation Council for Torture Victims (IRCT), Mexico City, Mexico, December 5-7.

Jaranson, J. M., \& Quiroga, J. (2011). Evaluating the services of torture rehabilitation programmes: History and recommendations. Torture, 21(2), 98-140. Retrieved from irct.org/assets/ uploads/1018-8185_2011-2_98-140.pdf

Kibler, J. L., Joshi, K., \& Ma, M. (2009). Hypertension in relation to posttraumatic stress disorder and depression in the U.S. national comorbidity survey. Behavioral Medicine, 34, 125132. doi/abs/10.3200/BMED.34.4.125-132

Kinzie, J., Riley, C., McFarland, B., Hayes, M., Boehnlein, J., Leung, P., \& Adams, G., (2008). High prevalence rates of diabetes and hypertension among refugee psychiatric patients. Fournal of Nervous and Mental Disease, 196(2), 108-112. doi: 10.1097/NMD.0b013e318162aa51

Kira, I. (2002). Torture assessment and treatment: The wraparound approach. Traumatology, 8, 2351. doi.org/10.1177/153476560200800203

Kivling-Boden, G., \& Sundbom, E. (2001). Life situation and posttraumatic symptoms: A follow-up study of refugees from the former Yugoslavia living in Sweden. Nordic fournal of Psychiatry, 55, 401-408. doi. org/10.1080/08039480152693291

Kivling-Boden, G., \& Sundbom, E. (2002). The relationship between post-traumatic symptoms and life in exile in a clinical group of refugees from the former Yugoslavia. Acta Psychiatrica Scandinavica, 105, 461-468. doi.org/10.1034/ j.1600-0447.2002.02247.x

Lambert, M.J., \& Barley, D.E. (2001). Research summary on the therapeutic relationship and psychotherapy outcome. Psychotherapy: Theory, Research, Practice, Training. 38(4), 357-361. doi:10
$.1037 \% 2 \mathrm{~F} 0033-3204.38 .4 .357$

Lie, B. (2002). A 3-year follow-up study of psychosocial functioning and general symptoms in settled refugees. Acta Psychiatrica Scandinavica, 106, 415-425. doi.org/10.1034/j.16000447.2002.01436.x

McFarlane, C. A., \& Kaplan, I. (2012). Evidencebased psychological interventions for adult survivors of torture and trauma: A 30-year review. Transcultural Psychiatry, 49(3-4), 539-567. doi.org/10.1177\%2F1363461512447608

Member Centers of the National Consortium of Torture Treatment Programs (NCTTP). (2015). Descriptive, inferential, functional outcome data on 9,025 torture survivors over six years in the United States. Torture, 25(2), 34-60. Retrieved from irct.org/assets/ uploads/1018-8185_2015-2_34-60.pdf

Mollica, R. F., Caspi-Yavin, Y., Bollini, P., Truong, T., Tor, S., \& Lavelle, J. (1992). The Harvard Trauma Questionnaire.: Validating a cross-cultural instrument for measuring torture, trauma, and post-traumatic stress disorder in Indochinese refugees. Fournal of Nervous and Mental Disease, 180(2), 111-116. doi/10.1097/00005053-199202000-00008

Montgomery, E., \& Patel, N. (2011). Torture rehabilitation: Reflections on treatment outcome studies. Torture, 21(2), 141145. Retrieved from irct.org/assets/ uploads/1018-8185_2011-2_141-145.pdf

Piwowarczyk, L. (2005). Torture and spirituality: Engaging the sacred in treatment. Torture, 15(1), 1-8. Retrieved from irct.org/assets/uploads/ Engaging\%20the \%20sacred.pdf

Raghavan, S., Rasmussen, A., Rosenfeld, B., \& Keller, A. S. (2013). Correlates of symptom reduction in treatment-seeking survivors of torture. Psychological Trauma: Theory, Research, Practice, and Policy, 5(4), 377-383. doi/10.1037/a0028118

Salo, C., \& Bray, E. (2016). Empirically-tested interventions for torture survivors: A systematic review through an ecological lens. [Special Issue: Trauma] Translational Issues in Psychological Science, 2(4), 449-463. doi/10.1037/tps0000097

Schwartz, C. E. Chesney, M. A., Irvine, M. J, \& Keefe, F. J. (1997). The control group dilemma in clinical research: Applications for psychosocial and behavioral medicine trials. Psychosomatic Medicine, 59, 362-371. doi=10.1.1.482.4005\&rep $=$ rep $1 \&$ type $=$ pdf

Spiric, Z., Opacic, G., Jovic, V., Samardzic, G., Knezevic, G., Mandic-Gajic, G., \& Todorovic, M. (2010). Gender differences in victims of war torture: Types of torture and psychological 
consequences. Vojnosanit Pregl, 67(5), 411-418. doi $=10.2298 / \mathrm{vsp} 1005411 \mathrm{~s}$

Stammel, N., Knaevelsrud, C., Schock, K., Walther, L. C. S., Wenk-Ansohn, M., \& Bottche, M. (2017). Multidisciplinary treatment for traumatized refugees in a naturalistic setting: Symptom courses and predictors. European fournal of Psychotraumatology, 8(2), 1-13. doi.org/ 10.1080/20008198.2017.1377552

Vieweg, W. V. R., Julius, D. A., Bates, J., Quinn III, J. F., Fernandez, A., Hasnain, M., \& Pandurangi, A. K. (2007). Posttraumatic stress disorder as a risk factor for obesity among male military veterans. Acta Psychiatrica Scandinavica, 116(6), 483-487. doi/abs/10.1111/j.1600-0447.2007.01071.x

Winokur A., Winokur D. F., Rickels K., \& Cox, S. S. (1984). Symptoms of emotional distress in a family planning service: Stability over a fourweek period. British fournal of Psychiatry,144, 395-399. doi: 10.1192/bjp.144.4.395

World Health Organization (WHO). (2001). The international classification of functioning, disability, and health (ICF). Geneva: WHO. 